Presented at the $4^{\text {th }}$ International Meeting on Electrochromism, August 21-23, 2000, Uppsala, Sweden and to be published in Electrochimica Acta.

\title{
ELECTROCHROMISM IN COPPER OXIDE THIN FILMS
}

\author{
T. J. Richardson, J. L. Slack and M. D. Rubin \\ Building Technologies Department \\ Environmental Energy Technologies Division, \\ Ernest Orlando Lawrence Berkeley National Laboratory, \\ University of California \\ 1 Cyclotron Road \\ Berkeley, California 94720 USA
}

August 15, 2000

This work was supported by the Assistant Secretary for Energy Efficiency and Renewable Energy, Office of Building Technologies, Building Systems and Materials Division of the US Department of Energy under Contract No. DE-AC03-76SF00098. 


\title{
ELECTROCHROMISM IN COPPER OXIDE THIN FILMS
}

\author{
T. J. Richardson, J. L. Slack and M. D. Rubin \\ Building Technologies Department \\ Environmental Energy Technologies Division, \\ Ernest Orlando Lawrence Berkeley National Laboratory, \\ Berkeley, California 94720 USA \\ tjrichardson@lbl.gov, http://windows.lbl.gov
}

\begin{abstract}
Transparent thin films of copper(I) oxide prepared on conductive $\mathrm{SnO} 2: \mathrm{F}$ glass substrates by anodic oxidation of sputtered copper films or by direct electrodeposition of $\mathrm{Cu} 2 \mathrm{O}$ transformed reversibly to opaque metallic copper films when reduced in alkaline electrolyte. In addition, the same $\mathrm{Cu} 2 \mathrm{O}$ films transform reversibly to black copper(II) oxide when cycled at more anodic potentials. Copper oxide-to-copper switching covered a large dynamic range, from $85 \%$ and $10 \%$ photopic transmittance, with a coloration efficiency of about $32 \mathrm{~cm} 2 / \mathrm{C}$. Gradual deterioration of the switching range occurred over 20 to 100 cycles. This is tentatively ascribed to coarsening of the film and contact degradation caused by the $65 \%$ volume change on conversion of $\mathrm{Cu}$ to $\mathrm{Cu} 2 \mathrm{O}$. Switching between the two copper oxides (which have similar volumes) was more stable and more efficient $(\mathrm{CE}=60 \mathrm{~cm} 2 / \mathrm{C})$, but covered a smaller transmittance range (60\% to $44 \% \mathrm{~T})$. Due to their large electrochemical storage capacity and tolerance for alkaline electrolytes, these cathodically coloring films may be useful as counter electrodes for anodically coloring electrode films such as nickel oxide or metal hydrides.
\end{abstract}

\section{Introduction}

The anodic formation and complex electrochemical properties of copper oxide films on bulk copper electrodes in alkaline electrolytes have been studied extensively. [1-7] While there is some controversy surrounding the precise sequence of compounds produced on the electrode surface, it is clear that copper(I) oxide, $\mathrm{Cu}_{2} \mathrm{O}$ is produced, followed by copper(II) oxide, $\mathrm{CuO}$. Due to the poor electronic conductivity of stoichiometric $\mathrm{Cu}_{2} \mathrm{O}$, the two oxides can coexist with copper. The oxide films can persist only within a narrow $\mathrm{pH}$ range.[8] Both oxides are semiconductors, $\mathrm{Cu}_{2} \mathrm{O}$ having a direct bandgap of about $2.1 \mathrm{eV},[9,10]$ and therefore strongly absorbing at wavelengths below $600 \mathrm{~nm}$, with a reddish appearance. $\mathrm{CuO}$, with $\mathrm{E}_{\mathrm{g}}=1.3$,[11] is absorbing throughout the visible spectrum. While thin $\mathrm{Cu}_{2} \mathrm{O}$ films with high transparency can easily be made by a variety of routes, and electrochromic behavior has been reported [12-14] on lithium intercalation of $\mathrm{Cu}_{\mathrm{x}} \mathrm{O}$ films, electrochromic devices based on interconversion of $\mathrm{Cu}$ and $\mathrm{Cu}_{2} \mathrm{O}$, or of $\mathrm{Cu}_{2} \mathrm{O}$ and $\mathrm{CuO}$ do not appear to have been investigated. Unlike electrochromic devices based on reflective metal films (typically bismuth or silver) that are alternately deposited and stripped, the present system involves transformations from metal to oxides in an intact film. 


\section{Experimental}

All films were deposited on $\mathrm{SnO}_{2}: \mathrm{F}$ coated glass substrates. Metallic copper films were prepared by DC magnetron sputtering from an oxygen-free high conductivity $\mathrm{Cu}$ target in an argon atmosphere at a pressure of $10 \mathrm{mTorr}$. Typical base pressure was $2.0 \times 10^{-6}$ Torr. With applied power of $100 \mathrm{~W}$, a $30 \mathrm{~nm}$ film was deposited in $3 \mathrm{~m} . \mathrm{Cu}_{2} \mathrm{O}$ films were prepared by DC magnetron reactive sputtering using the same target. Ar $(99.9995 \%)$ was delivered through the sputter gun, across the target surface at $240 \mathrm{sccm}$. The $\mathrm{O}_{2}(99.998 \%)$ flow rate was $5.3 \mathrm{sccm}$, directed at the substrate from below. The total process pressure was $21.3 \mathrm{mTorr}$, with oxygen partial pressure estimated to be between 1.0 and 1.5 mTorr. Copper oxide films were also electrodeposited from alkaline copper sulfate/lactic acid solutions according to the method of Mukhopadhyay et al. [15] Film thicknesses were measured by profilometry (Dektak). Electrochemical oxidation and cycling of films were carried out in a $50 \mathrm{~mL}$ fused silica cuvette containing $0.1 \mathrm{M} \mathrm{NaOH}$ electrolyte, using a platinum foil counter electrode and an $\mathrm{HgO} / \mathrm{Hg}$ reference electrode (Radiometer). Photopic transmittance was monitored by an International Light silicon detector with output coupled to the computerized potentiostat/galvanostat (Arbin, Inc.). Visible spectra were recorded using a fiber optic spectrometer (Ocean Optics). X-ray diffraction (XRD) patterns of films as deposited and after cycling were obtained using a Siemens thin film diffractometer with an incident beam angle of $0.5^{\circ}$ from the sample surface.

\section{Results}

XRD patterns obtained from a freshly prepared, $40 \mathrm{~nm}$ thick copper film (Fig. 1, trace a) contained strong peaks due to metallic $\mathrm{Cu}$ and the underlying $\mathrm{SnO} 2: \mathrm{F}$ layer. Some very weak reflections due to $\mathrm{Cu} 2 \mathrm{O}$ can be discerned. The crystallite size, estimated from the peak width, is $12 \mathrm{~nm}$. The visible transmission spectrum of this sample, uncorrected for the substrate, is shown in Figure 2 (bottom trace). The presence of a native oxide layer on the surface of the copper films inhibited the anodic conversion of $\mathrm{Cu}$ to $\mathrm{Cu} 2 \mathrm{O}$ unless it was first reduced by sweeping cathodically to $-900 \mathrm{mV}$ (Fig.3). A slight decrease in transmittance accompanied the reduction peak at $-0.63 \mathrm{~V}$. On the first anodic sweep, copper was oxidized to $\mathrm{Cu} 2 \mathrm{O}$ at $0.05 \mathrm{~V}$, with rapid bleaching of the film. Subsequent cycles were similar to that shown in Figure 4, except that the height of the peaks increases over the first three or four cycles, with a corresponding increase in the optical switching range. Reduction to copper metal

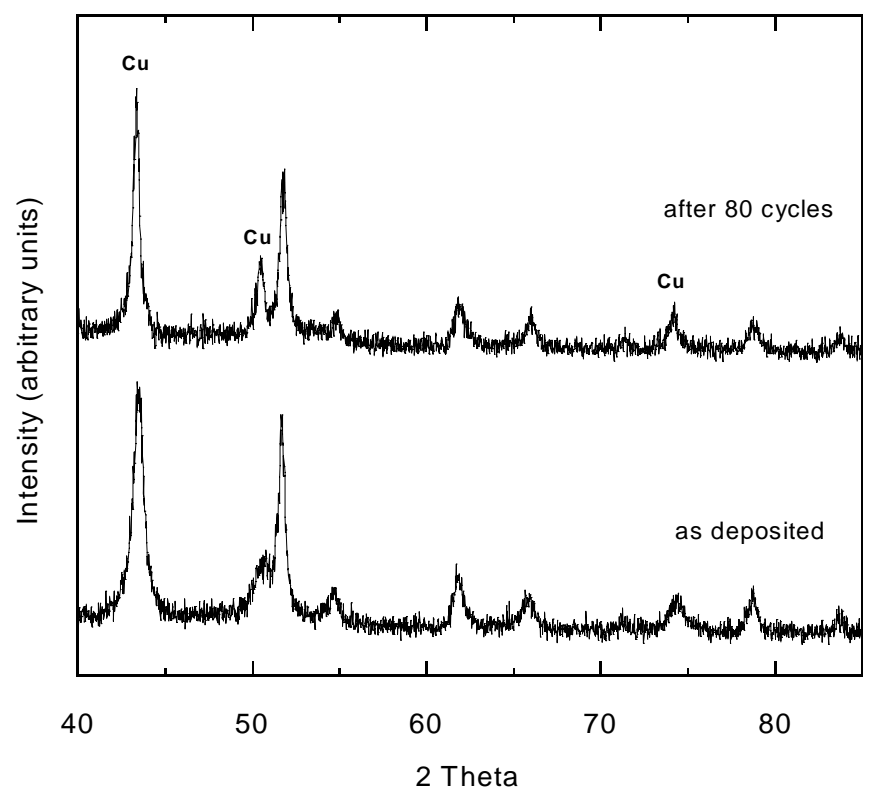

Figure 1. XRD patterns of Sputter-deposited copper films on SnO2:F glass. Unlabelled peaks are due to $\mathrm{SnO2:F}$. 


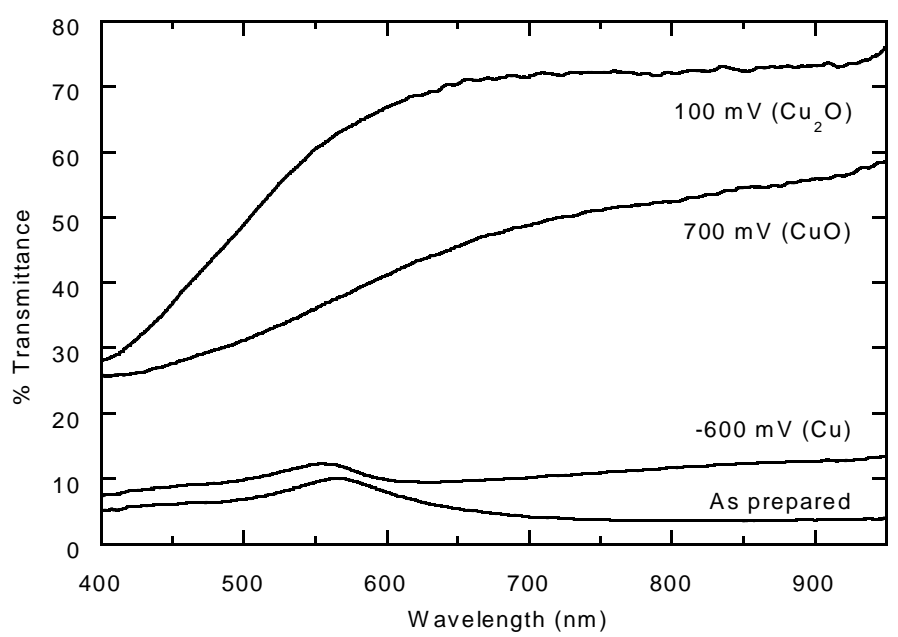

Figure 2. Visible transmittance spectra obtained in situ during electrochemical cycling of copper/copper oxide films.

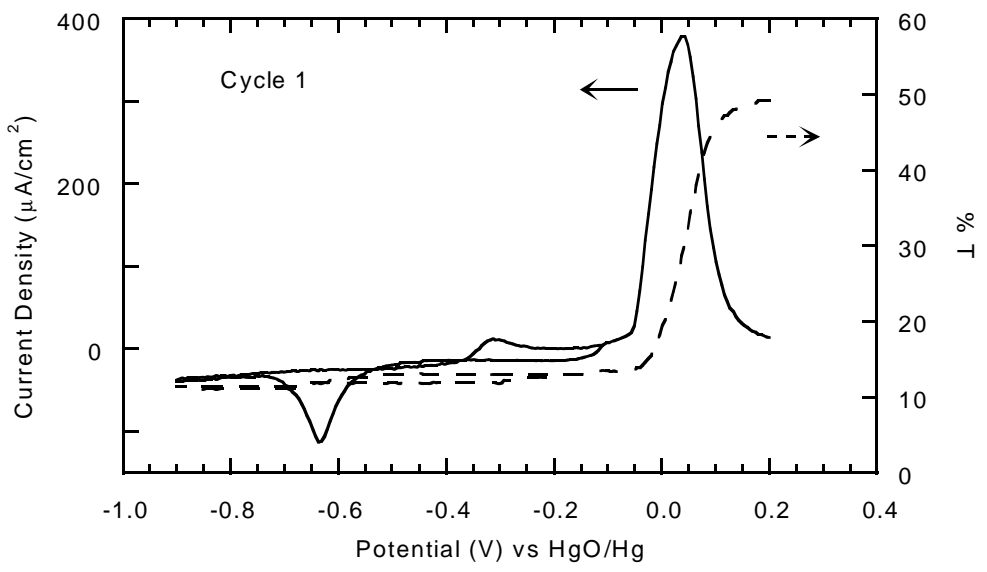

Figure 3. First cathodic and anodic sweeps for $40 \mathrm{~nm}$ sputtered copper film (1 mV/s, $0.1 \mathrm{M} \mathrm{NaOH})$. takes place beginning at -0.4 $\mathrm{V}$, becoming rapid at $-0.8 \mathrm{~V}$. The shape of the reduction curve strongly suggests a nucleation mechanism. The re-oxidation of the copper film proceeds in three distinct steps at $-0.3 \mathrm{~V}, 0.0 \mathrm{~V}$, and 0.2 $\mathrm{V}$. Bleaching of the film occurs at each step, but with coloration efficiencies of 54 , 29 , and $35 \mathrm{~cm} 2 / \mathrm{C}$, respectively. The recovered $\mathrm{Cu}$ film is somewhat more crystalline (est. size $20 \mathrm{~nm}$ ) than the initial deposit.

Visible transmission spectra of this electrode in the three different states are presented in Figure 2. In the $\mathrm{Cu}_{2} \mathrm{O}$ state, the film is quite clear and only slightly yellow in appearance. The copper state obtained by reduction of this oxide is not as reflecting as the original sputtered film, but is still mirror-like. The highest quality copper state was found after polarizing the electrode at $-0.6 \mathrm{~V}$ for an extended period, rather than sweeping rapidly to more negative potentials. The dark

state produced by anodic polarization, referred to as "CuO", begins to appear at $0.2 \mathrm{~V}$ (Fig. 5). Despite the black color of $\mathrm{CuO}$, the switching here is limited to about $20 \%$. Polarization beyond $0.7 \mathrm{~V}$ resulted in oxygen evolution and no further darkening of the film. An XRD pattern obtained from this electrode (Fig. 6), removed from the electrolyte in its darkest state, shows the poorly crystalline nature of the copper oxide layer. Very weak reflections due to $\mathrm{CuO}$ are discernable, with somewhat stronger reflections from $\mathrm{Cu}_{2} \mathrm{O}$.

Sputtered $\mathrm{Cu}_{2} \mathrm{O}$ films contained small amounts of $\mathrm{Cu}$ and had a deep copper color. Oxidation following reduction of the entire film to copper produced a clear, highly transparent, and strongly adherent $\mathrm{Cu}_{2} \mathrm{O}$ film, which exhibited superior cycling stability to the mainly metallic precursor films described above. Electrodeposited $\mathrm{Cu}_{2} \mathrm{O}$ was less uniform and adherent, but could be cycled several times over a wide range of visible transmittance. 


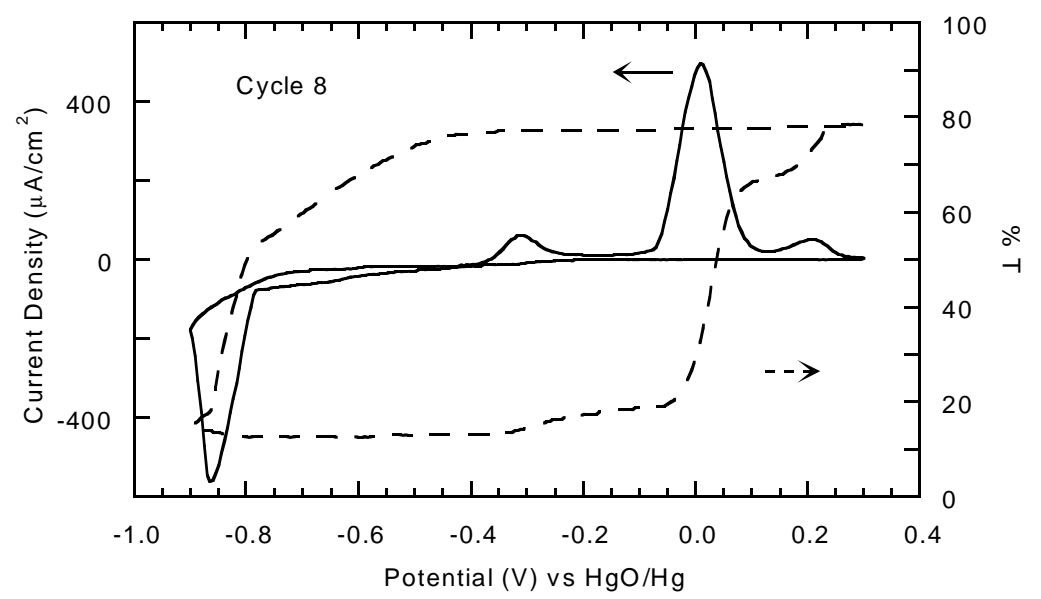

Figure 4. Eighth cycle, same electrode and conditions as Fig. 3.

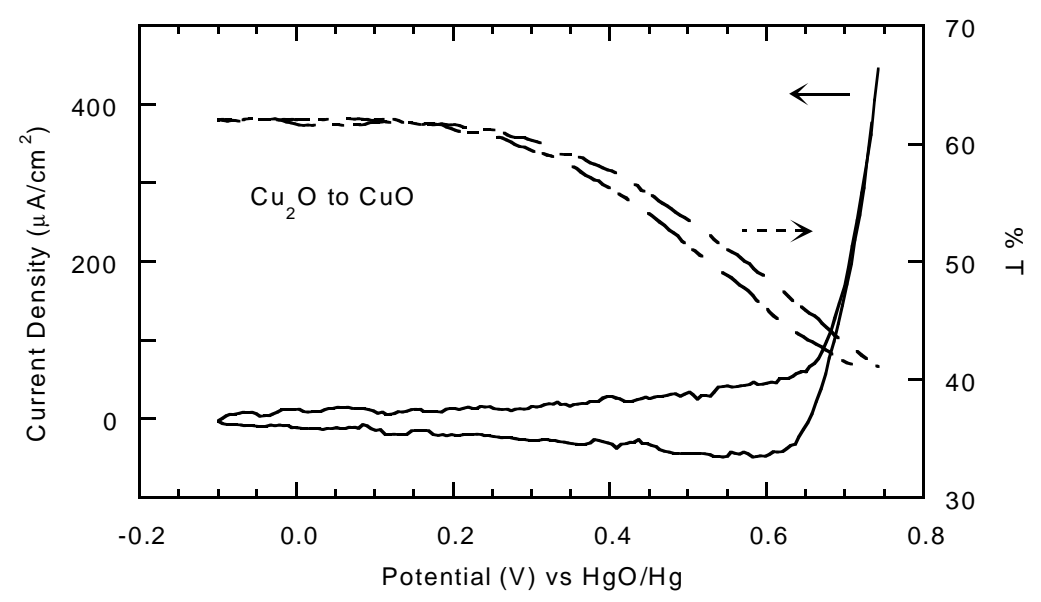

Figure 5. High potential region ( $1 \mathrm{mV} / \mathrm{s}, 0.1 \mathrm{M} \mathrm{NaOH})$.

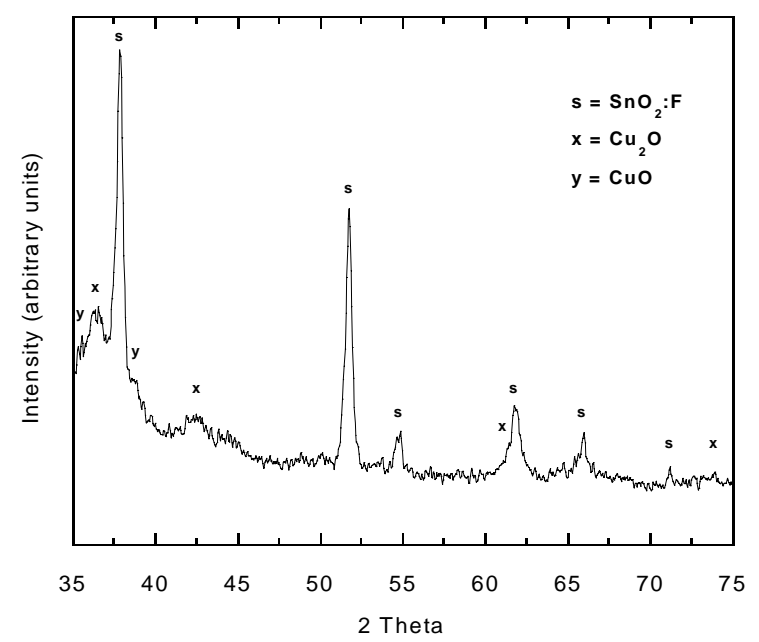

Figure 6. XRD pattern of electrode from Fig. 5.

\section{Discussion}

The electrochemical behavior of these copper/copper oxide films and the phases present at different potentials are consistent with results for bulk copper in similar electrolytes. [1-7] In the latter case, however, continuing oxidation of the underlying copper causes some overlapping of anodic peaks. The absence of cathodic features prior to $\mathrm{Cu}_{2} \mathrm{O}$ reduction to $\mathrm{Cu}$ in our experiments (but seen on bulk copper) may be due to the low conductivity of $\mathrm{Cu}_{2} \mathrm{O}$. It is not until dendrites of $\mathrm{Cu}$ have begun to penetrate the oxide that reduction can proceed at a significant rate. The nucleation and dendritic growth of $\mathrm{Cu}$ from the oxide may also account for the coarsening of the metallic copper film relative to the original. Poor conductivity in $\mathrm{Cu}_{2} \mathrm{O}$ may also contribute to the difficulty of converting it to $\mathrm{CuO}$ at higher potentials.

Dissolution of copper species in the electrolyte does not appear to play a significant role in the electrochromic processes described here. Extensive dissolution would result in irreversible loss of copper due to the large quantity $(40 \mathrm{~mL})$ of electrolyte and small electrode area (5-6 $\mathrm{cm}^{2}$ ). In addition, redistribution of material over the surface was not observed, and portions of the film at 
different distances from the counter electrode behaved identically. Nor were deposits observed to accumulate on the counter electrode.

Crystalline metallic copper contains $85 \mathrm{Cu}$ atoms $/ \mathrm{nm}^{3}$. [16] $\mathrm{In} \mathrm{Cu}_{2} \mathrm{O}$, there are $52 \mathrm{Cu}$ atoms $/ \mathrm{nm}^{3}$ [17], corresponding to a volume expansion on forming the oxide of $65 \%$. This expansion and contraction eventually fractures the film and, along with the coarsening of the particles, reduces its reflectivity in the metallic state, while increasing the transparency of the oxide states. This may help to explain the relative stability of sputtered $\mathrm{Cu}_{2} \mathrm{O}(\mathrm{Cu})$ films, which have an intermediate original volume. Conversion of $\mathrm{Cu}_{2} \mathrm{O}$ to $\mathrm{CuO}$ (49 atoms $/ \mathrm{nm}^{3}$ [18]), however, involves little volume change and minimal rearrangement of the structure. This, combined with the inability to completely interconvert the two oxides, may contribute to the good cyclability in the high potential region. Interestingly, the intermediate $\mathrm{Cu}(\mathrm{I}), \mathrm{Cu}(\mathrm{II})$ oxide, $\mathrm{Cu}_{4} \mathrm{O}_{3}$ [19], does not appear to be formed during oxidation of $\mathrm{Cu}_{2} \mathrm{O}$.

The oxidation of copper to $\mathrm{Cu}_{2} \mathrm{O}$ in three steps is intriguing. The first peak $(-0.3 \mathrm{~V})$ appears during oxidation of bulk copper, and has been attributed to formation of a surface oxide layer. Its magnitude, however, increases somewhat as the copper particles become larger. This step represents about $12 \%$ of the total charge required to reach the maximum transparency. Some lower oxides of copper, designated $\mathrm{Cu}_{8} \mathrm{O}$ and $\mathrm{Cu}_{4} \mathrm{O}$ have been observed by electron diffraction on partially oxidized copper surfaces. It is possibile that formation of an intermediate lower oxide is responsible for this feature. In situ XRD experiments are planned to investigate the nature of these three steps.

\section{Conclusions}

The copper-to-copper oxide transition reveals a new, cathodically coloring, electrochromic system, which combines a highly reflecting metallic state with a highly transparent insulating state. Devices pairing it with passive or anodically coloring counter electrodes (such as nickel oxide or a hydride mirror electrode) may offer a unique range of transmitting and reflecting states. The copper(I)-to-copper(II) oxide transition may also be useful in such a device or, given improvements in the switching range, may find its own applications.

\section{Acknowledgment}

This work was supported by the Assistant Secretary for Energy Efficiency and Renewable Energy, Office of Building Technologies, Building Systems and Materials Division of the U.S. Department of Energy under Contract No. DE-AC03-76SF00098. The authors thank Dr. Robert Kostecki of LBNL for helpful discussions.

\section{References}

[1] H. Y. H. Chan, C. G. Takoudis, M. J. Weaver, J. Phys. Chem. B, 103, 357 (1999).

[2] S. Hartinger, B. Pettinger, K. Doblhofer, J. Electroanal. Chem., 397, 335 (1995).

[3] W. Kautek, J. G. Gordon, J. Electrochem. Soc., 137, 2672 (1990).

[4] J. C. Hamilton, J. C. Farmer, R. J. Anderson, J. Electrochem. Soc., 133, 739 (1986).

[5] S. T. Mayer, R. H. Muller, J. Electrochem. Soc., 139, 426 (1992).

[6] B. Miller, J. Electrochem. Soc., 116, 1675 (1969). 
[7] J. L. Ord, D. J. DeSmet, Z. Q. Huang, J. Electrochem. Soc., 134, 826 (1987).

[8] B. Beverskog, I. Puigdomenech, J. Electrochem. Soc., 144, 3476 (1997).

[9] T. D. Golden, M. G. Shumsky, Y. Zhou, R. A. NanderWerf, R. A. Van Leeuwen, J. A. Switzer, Chem. Mat., 8, 2499 (1996).

[10] M. T. S. Nair, L. Guerrero, O. L. Arenas, P. K. Nair, Appl. Surf. Sci., 150, 143 (1999).

[11] F. Marabelli, G. B. Parravicini, F. Salghetti-Drioli, Phys. Rev. B, 52, 1433 (1995).

[12] N. Ozer, F. Tepehan, Solar Energy Mat. Solar Cells, 30, 13 (1993).

[13] H. Demiryont, US Patent 4,830,471.

[14] F. I. Brown, S. C. Schulz, US Patent 5,585,959.

[15] A. K. Mukhopadhyay, A. K. Chakraborty, A. P. Chatterjee, S. K. Lahiri, Thin Solid Films, 209, 92 (1992).

[16] H. E. Swanson, E. Tatge, US NBS Circular 359, 1 (1953).

[17] R. Restori, D. Schwarzenbach, Acta Cryst. B, 42, 201 (1986).

[18] S. Asbrink, L. J. Lorrby, Acta Cryst. B, 26, 8 (1970).

[19] M. O’Keefe, J. O. Bovin, Am. Miner., 63, 180 (1978). 